\title{
EQUIPE MULTIDISCIPLINAR: APRESENTAÇÃO DE UM MODELO ASSISTENCIAL TRANSDISCIPLINAR
}

Autores: AMARAL, Márcio José Cardoso; BUCCO, José Roberto Melchiori; MILMAN, Mauro Henrique de Sá Adami

Introdução

Em serviços de assistência à saúde, um dos principais objetivos das políticas institucionais é melhorar a eficiência da utilização de recursos assistenciais, atuando principalmente na redução de riscos evitáveis, como infecções hospitalares, trombose venosa profunda e quedas. A equipe multiprofissional tem um papel de grande importância neste planejamento e atuação, de forma a tornar o período de internação e o processo de desospitalização o menos traumático possível. Desenvolveu-se um programa transdisciplinar: no qual cada membro da equipe multidisciplinar passou a intervir nas outras especialidades afins, visando uma maior eficiência dos processos terapêuticos e de alta hospitalar.

\section{Método}

O estudo foi realizado num hospital geral secundário com 150 leitos de internação e 10 leitos de uti adulto. Avaliou-se dois períodos de 9 meses. No segundo período Inicialmente foi realizada a estruturação de planejamentos terapêuticos de todos os membros da equipe multidisciplinar, elencando metas de trabalho. Após sedimentação das rotinas, modificou-se a atuação dos integrantes da equipe multidisciplinar para uma forma transdisciplinar de atuação, criando assim um algoritmo cíclico de barreiras segmentares que culminam com o processo de desospitalização do paciente operado. Os indicadores analisados foram: tempo de permanência hospitalar pós-operatória, número de leitos virtuais, turnover de leitos, taxa de infecção relacionada a assistência à saúde e reinternações não programadas, em cirurgias abdominais de urgência. Sendo comparados aos resultados anteriores a implantação.

\section{Resultados}

Foram incluídos 872 pacientes. A análise dos indicadores demonstraram: redução do tempo médio de internação, da taxa de infecção relacionada a assistência à saúde e das reinternações não programadas (queda respectivamente de 20\%,21\% e 31\%) com resultados atuais respectivamente de 3,4 dias, 6,5 \% e 0,9\%. E aumento do número de leitos virtuais ( o aumento no número total de leitos virtuais em 5\%] e turnover de leitos com resultados atuais de 7,5 pacientes / leitos mês e 1,5 leitos virtuais /dia.

\section{Conclusão}

A organização e padronização do atendimento a saúde visando a desospitalização do paciente operado na urgência mostrou-se eficiente, mas antes de tudo mostrou ser um programa educativo a toda equipe de assistência à saúde.

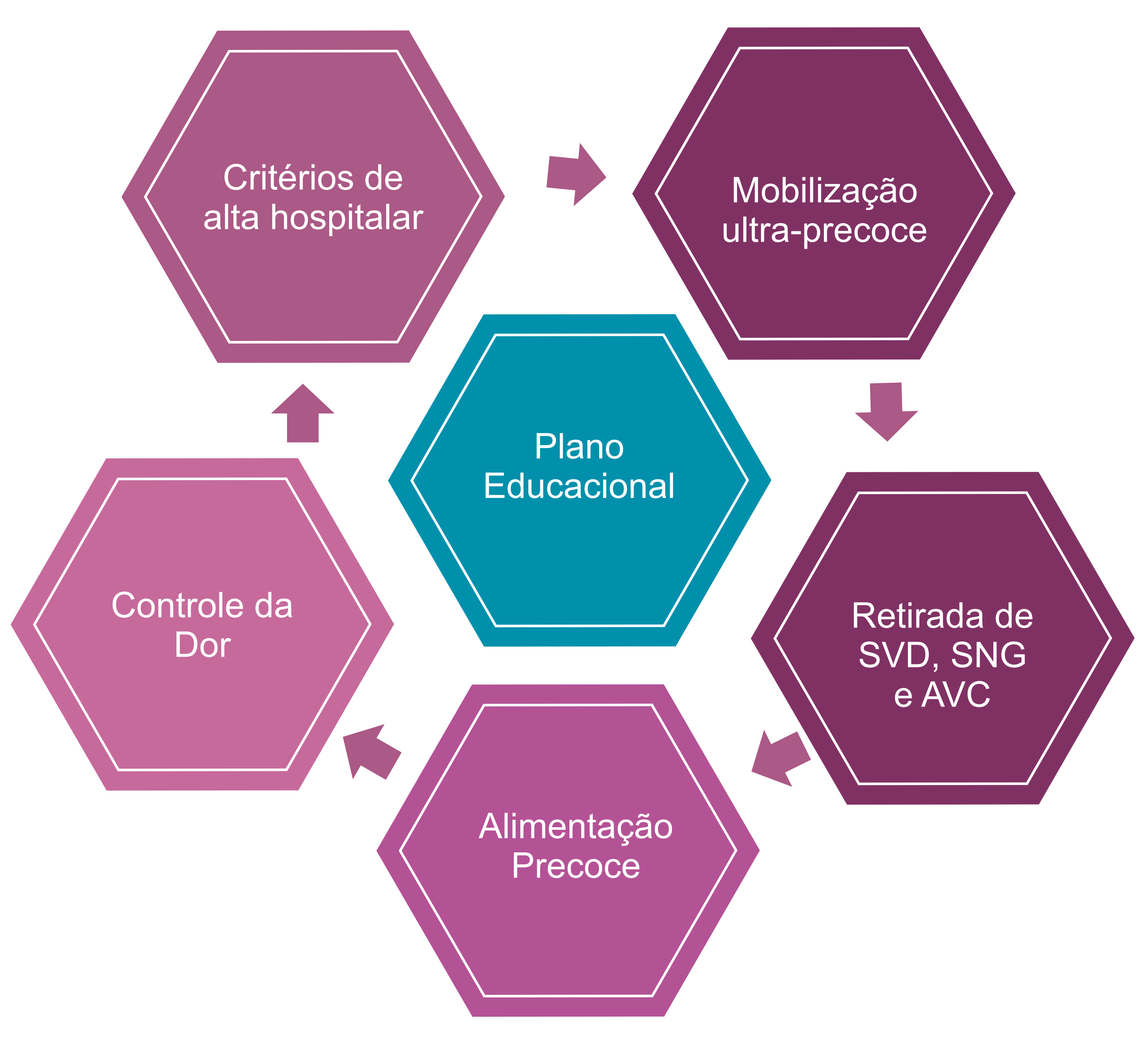

Pilares do atendimento ao paciente pós operatório

Relação Capacidade X Demanda Eficiência Operacional

Taxa de Ocupação e Saídas Hospitalares Clínica Cirúrgica - HRC

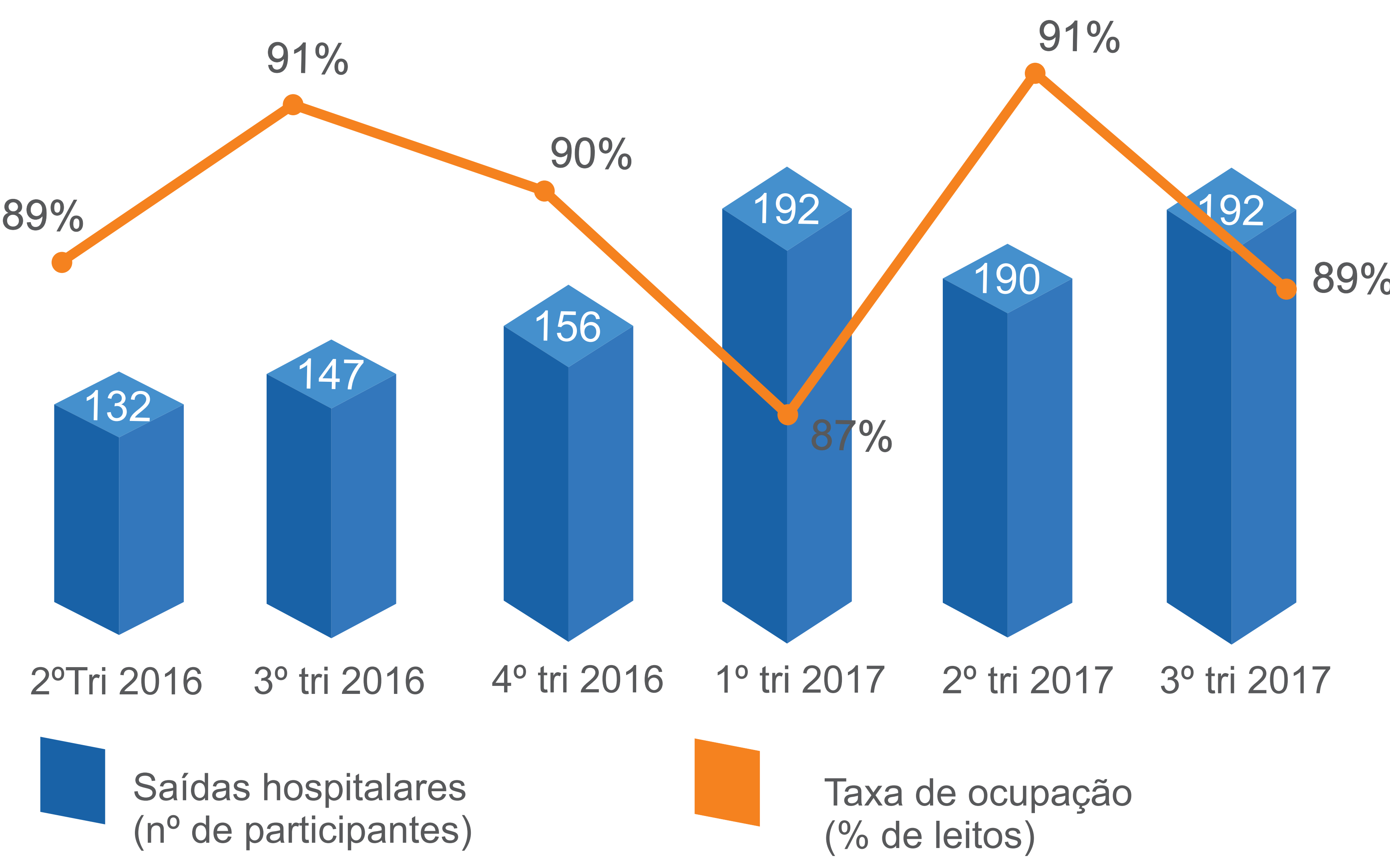

Criação de Leitos Virtuais e Tempo Médio de internação na Clínica Cirúrgica - HRC

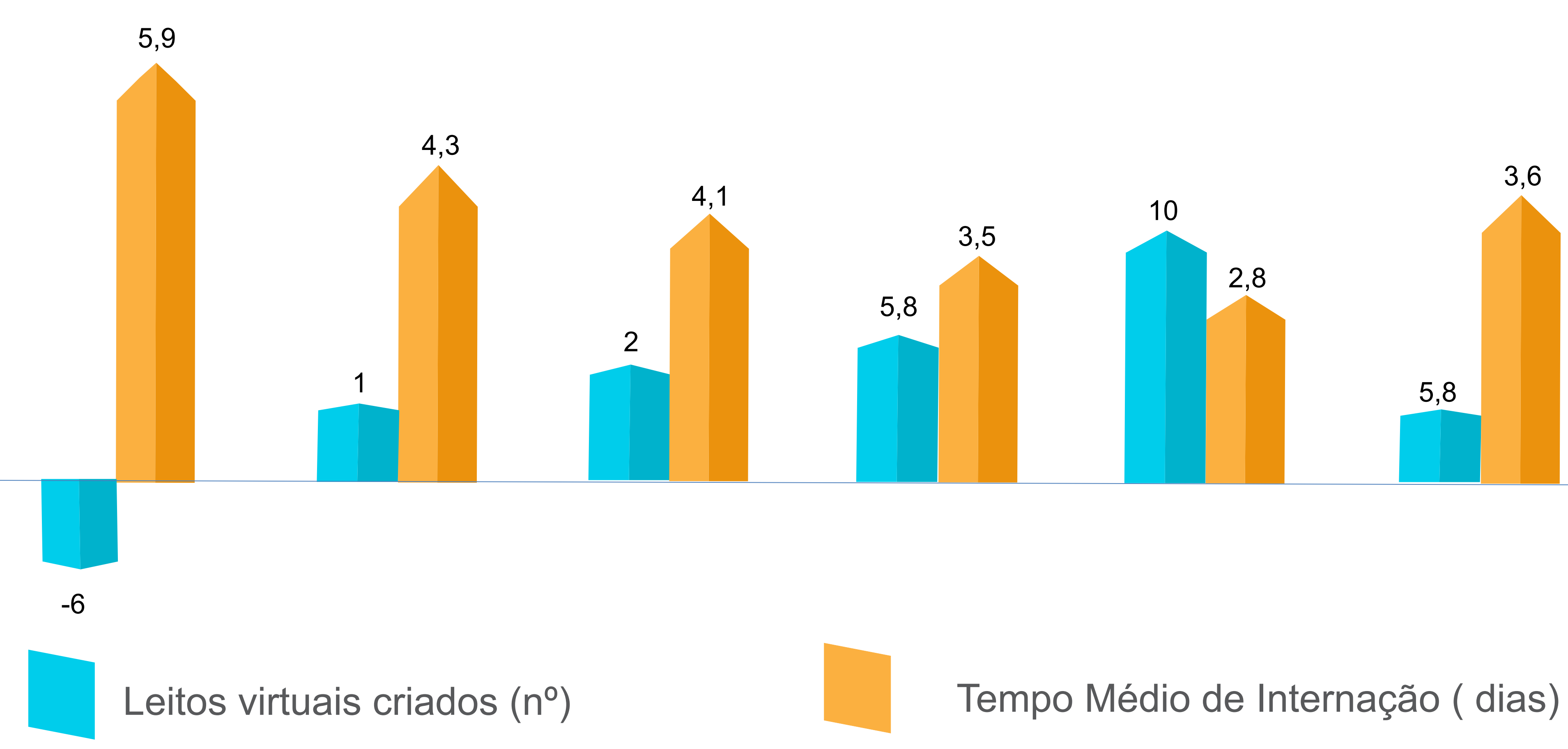

